\title{
Reactive Oxygen Species: Its Effects on various Diseases
}

\author{
Sandeep S Verma ${ }^{1}$, Swati Trivedi ${ }^{1}$, Rajneesh Prajapat ${ }^{2 *}$, Avinash Marwal $^{2}$ \\ ${ }^{1}$ Department of Molecular \& Cellular Engineering, Sam Higginbottom Institute of Agriculture Technology and \\ Sciences, Allahabad \\ sandeepsverma@rediffmail.com \\ ${ }^{1}$ Department of Molecular \& Cellular Engineering, Sam Higginbottom Institute of Agriculture Technology and \\ Sciences, Allahabad \\ iamswatitrivedi@gmail.com \\ ${ }^{2}$ Department of Science, Mody University of Science \&Technology, Lakshmangarh, Sikar, Rajasthan, India. \\ prajapat.rajneesh@gmail.com \\ ${ }^{2}$ Department of Science, Mody University of Science \&Technology, Lakshmangarh, Sikar, Rajasthan, India. \\ marwal_avinash@yahoo.co.in
}

\begin{abstract}
A free radical is any molecule capable of independent existence that contains one or more free electrons. These free radicals fall under the broader category of reactive oxygen species (ROS). ROS such as $\mathrm{O}_{2}^{-}, \mathrm{H}_{2} \mathrm{O}_{2}, \mathrm{NO}^{-}, \mathrm{OH}^{-}, \mathrm{HOCl}$, $\mathrm{ONOO}^{-}$are toxic to cells. ROS act largely by driving several important molecular pathways that play important roles in pathologic processes including neurodegeneration. injury, atherosclerosis, and inflammatory responses and ischemiareperfusion. ROS, as in various radicals ions leads to mitochondrial dysfunction and consequently other cell organelles damage either through environmental effect or through genetic or metabolic disorders. Reactive molecular species also disturbs other metabolic pathways in a manner that cell's normal functionality gets disrupted. Though diseases caused by reactive oxygen species are many, this review has covered its effect on major diseases. The present review paper will provide the detail of mechanism of ROS and its effect on different pathological states.
\end{abstract}

\section{Indexing terms/Keywords}

Oxidative stress; Reactive Oxygen Species; Free radicals; Pathogenesis.

\section{Academic Discipline And Sub-Disciplines}

Molecular Biology

\section{SUBJECT CLASSIFICATION}

Biotechnology

\section{TYPE (METHOD/APPROACH)}

Review Article

\section{Council for Innovative Research}

Peer Review Research Publishing System

\section{Journal: Journal of Advances in Biotechnology}

Vol 3, No. 1

\section{editor@cirjbt.com}

www.jbt.cirworld.com, www.cirworld.com 


\section{INTRODUCTION}

Oxygen is the vital element used for the aerobic life processes. Nearly about $5 \%$ and more of the inhaled $\mathrm{O}_{2}$ is converted into reactive oxygen species (ROS) (1), such as $\mathrm{O}_{2}^{-}, \mathrm{H}_{2} \mathrm{O}_{2}, \mathrm{NO}$, by the univalent reduction of $\mathrm{O}_{2}$ by the electron transfer system in mitochondria. The increase in ROS production threatens the cells under the aerobic conditions which derive their energy from the reduction of oxygen, and thus are protected by the antioxidant system of the cells. The imbalance between the ROS production and antioxidant system of the cell causes Oxidative Stress which leads to the cellular dysfunction causing various diseases. Free radicals, superoxide $\left(\mathrm{O}_{2}^{-}\right)$, hydrogen peroxide $\left(\mathrm{H}_{2} \mathrm{O}_{2}\right)$, and nitric oxide (NO) are three free radical reactive oxygen species (ROS) that are essential for normal physiology, but also accelerating a cell death through necrotic or apoptotic mechanism (Figure. 1).

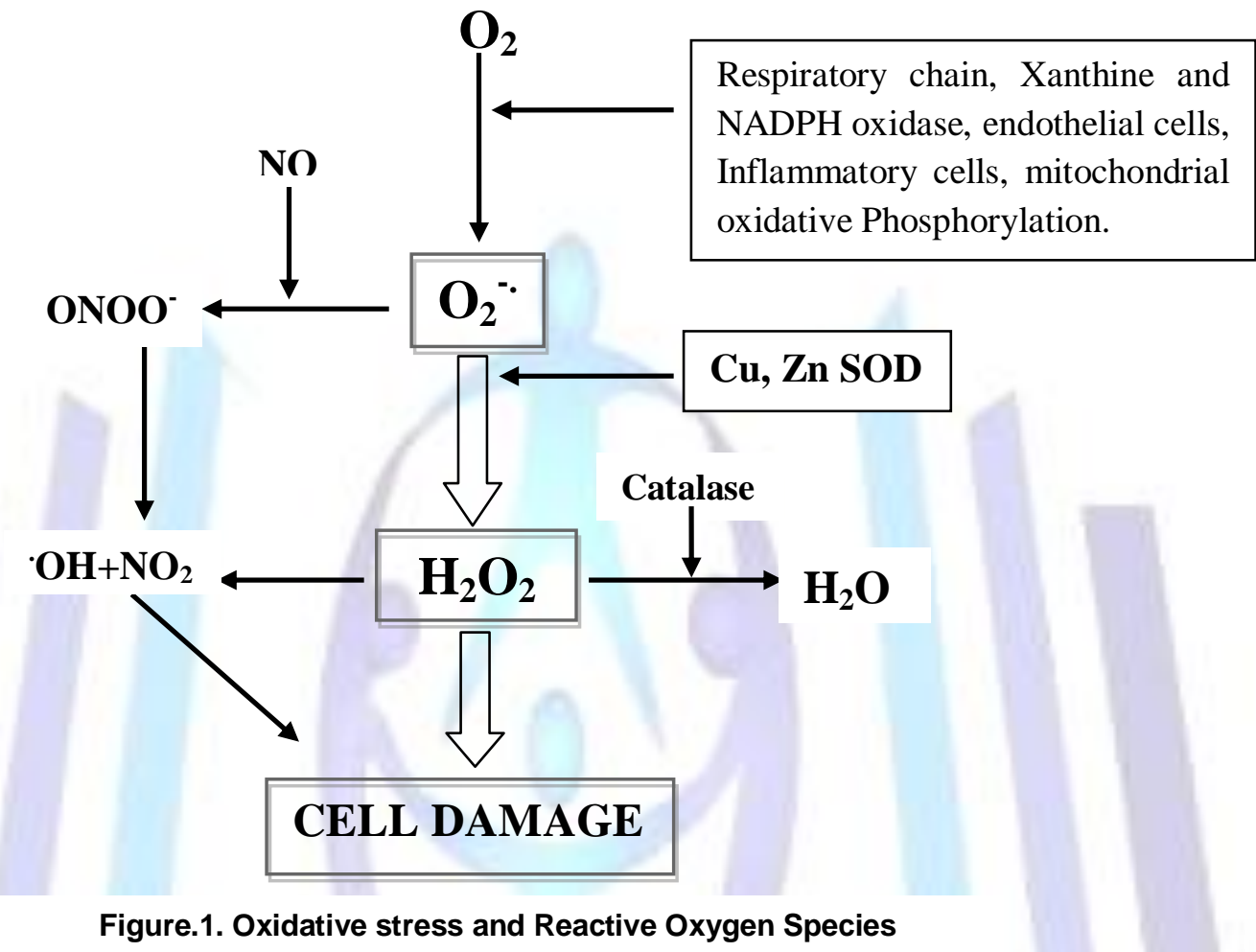

Harmful effects of ROS on the cell can be described as DNA damage, Lipid peroxidation and Oxidations of amino acids in proteins, Inactivation of specific enzymes by oxidation of co-factors. In diseases such as Alzheimer's disease, rheumatoid arthritis, multistage carcinogenesis, cerebral and cardiac ischemia, inflammatory bowel disease, and aging which are mostly caused by ROS (Figure. 2) has been extensively studied.with specific emphasis on their molecular characterization.

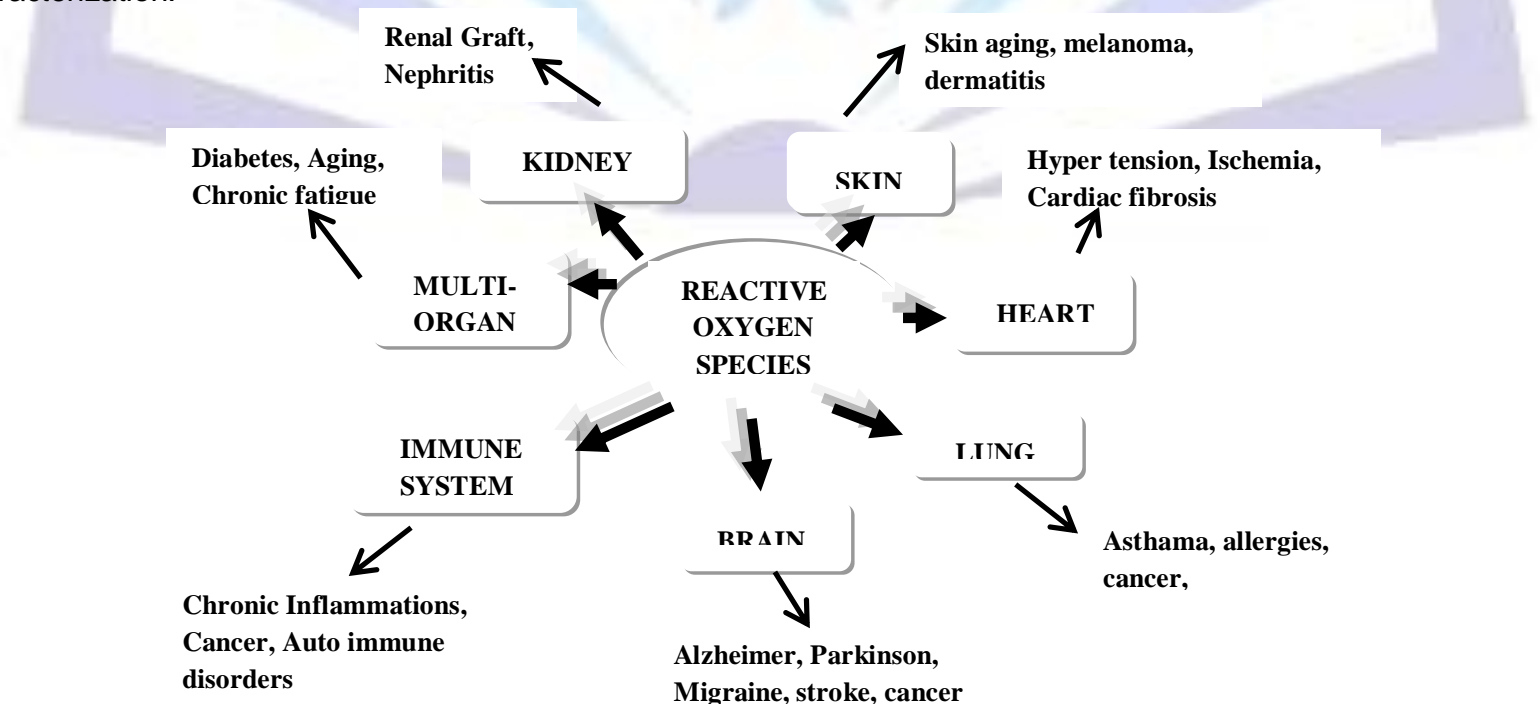

Figure.2. Effect of Reactive Oxygen Species on various Organs 


\section{Superoxide $\left.\left(\mathrm{O}_{2}\right)^{-}\right)$}

Superoxide $\left(\mathrm{O}_{2}^{-}\right)$is generated by the mitochondrial electron transfer chain during the oxidation of reduced nicotinamide adenine dinucleotide (NADH) to oxidized nicotinamide adenine dinucleotide (NAD), and also as a by product of many enzymes that act as oxidases(2). The beneficial effects of $\mathrm{O}_{2}^{-}$include regulation of vascular function, cell division, inflammation, apoptosis, and bactericidal activity of neutrophils (3) whereas, decreased levels of $\mathrm{O}_{2}^{-}$can lead to an increased susceptibility to bacterial infections.

\section{Hydrogen peroxide $\left(\mathrm{H}_{2} \mathrm{O}_{2}\right)$}

superoxide dismutase catalyzed dismutation of $\mathrm{O}_{2}$ as well as many other enzymatic reactions causes production of Hydrogen peroxide $\left(\mathrm{H}_{2} \mathrm{O}_{2}\right)$. $\mathrm{H}_{2} \mathrm{O}_{2}$ can diffuse across membranes and through the cytosol unlike $\mathrm{O}_{2}^{-}$, which remains at the site of production (4). Since $\mathrm{H}_{2} \mathrm{O}_{2}$ is a powerful oxidizing agent, cells express abundant catalase, glutathione (GSH), and thioredoxin (Trx) that convert $\mathrm{H}_{2} \mathrm{O}_{2}$ to water. Reaction of $\mathrm{H}_{2} \mathrm{O}_{2}$ with free $\mathrm{Fe}^{2-}$ causes oxidation of iron and production of hydroxyl radicals. Hydroxyl radical production has many severe cocsequences, including loss of vasodilation which can lead to tissue hypoxia and endothelial injury (5).

\section{Nitric oxide (NO)}

Cytosolic activity of enzyme known as NO synthase (NOS) causes generation of NO which plays a major role by activating the soluble guanylate cyclases that regulates the ion channels and thus regulating vascular tone. Apart from it through direct inhibition of cytochrome oxidase NO modulates cellular respiration by competitively occupying the oxygen binding site of enzyme (6). Recovery from neuronal injury is promoted by NOS inhibitors (7). It is also believed to act as a neurotransmitter regulating neuronal channel (8). Endothelial NO produces vasodilation that can improve blood flow under ischemic insult,, but neuronal $\mathrm{NO}$ is produced during downstream of calcium dysregulation and can prevent energy generation in the mitochondria (9). Apart from it most importantly, in certain environments NO acts as an antioxidant and prevents the lipid peroxidation (10).

\section{PATHOLOGICAL EFFECTS}

\section{Cancer}

Instead of the fact that they are opposite ROS plays a key role in both Apoptosis and Cancer (11). In addition, oxidative DNA damage has been clearly linked to induction of carcinogenesis (12) and, 8-oxo-2'-deoxyguanosine, the DNA oxidative product has been reported to be highly mutagenic (13). Contribution to carcinogenesis of ROS is through interference with signal cascade systems, which among others included, the nuclear transcription factor kappa B (NFkB), activated protein-1 (AP-1), phospholipase A2, mitogen-activated protein kinases (MAPKs) and c-Jun kinase (14-18). Rapid reaction of cells to redox imbalance is through a plethora of biological responses, including cell cycle-specific growth arrest, gene transcription, and initiation of signal transduction pathways and repair of damaged DNA. These early events are likely to determine whether a cell will necrose, senesce, apoptose or survive and proliferate (19). Inhibition of apoptosis, follicular lymphomas, and carcinomas with p53 mutations causes tumors such as: lung cancer, colorectal cancer, medullary breast carcinoma; and hormone-dependent tumours: such as breast, prostate and ovarian cancer (2022).

Apoptosis can be initiated by a variety of stimuli, oxidants, including, glucocorticoids, hyperthermia growth-factor or hormone withdrawal, ionizing radiation and multiple classes of chemotherapeutic agents (23-24). The stress exerted on the cell provides its viability. Following an apoptotic signal, progression in lipid peroxidation due to cells sustains. leads ROS and oxidative damage in the induction of apoptosis (25-28). The protein $\mathrm{Bcl}-2$ protects against apoptosis by blocking cytochrome $c$ release hence this protein may have an antioxidant function (29-34). It is suggested that oxygen inhibits the proliferation of human lymphocytes and fibroblasts (35-37). ROS as a mediator of apoptosis acts by decreasing intracellular glutathione, the major buffer of the cellular redox status and/or by increasing cellular reactive species (37-41). $\mathrm{H}_{2} \mathrm{O}_{2}$ at low doses induces apoptosis via production of $\mathrm{OH}^{-}$radicals and alteration of the oxidant/antioxidant pathway (4243). a proton gradient and superoxide radicals is generated by Mitochondrial respiration, causing alkaline-induced cell death, mitochondrial integrity and oxidative stress (44).

\section{Diabetes}

Diabetes mellitus is a group of metabolic diseases. It is characterized by hyperglycemia resulting from defects in secreation of insulin or insulin action, sometimes both (45). Several other factors like hyperlipidemia and enhanced oxidative stress play a major role in diabetic pathogenesis besides hyperglycemia. At this level the progression of disease will be at high risk (46-47).

Chronic diseases, such as atherosclerosis, diabetes and rheumatoid arthritis are common end points of oxidative stress and oxidative damage to the tissue (48). Oxidative stress is currently suggested as mechanism underlying diabetes and diabetic complic ations (49) as persistent hyperglycemia causes increased production of reactive oxygen species (ROS). Increasing production and/ or decreased destruction of nonenzymic and enzymic catalase (CAT), reduced glutathione (GSH), and superoxide dismutase (SOD) (highly reactive) antioxidants of aerobic respiration that is where $\mathrm{O}_{2}$ is commonly produced. SOD which is primarily produced is the front line of defense against ROS-mediated injury (51).

Lipids when react with free radicals, they undergo peroxidation to form lipid peroxides decomposing to form numerous products including malondialdehyde. In nervous system injury in diabetes,a one unifying mechanism causes both 
metabolic and vascular insults to be increased by cellular oxidative stress and impairing the function of mitochondria (53, 54). Through in vivo and in vitro measurement of oxidative stress in sensory neurons as well as neuronal protection by antioxidants this hypothesis have been supported. In vitro, $\mathrm{O}_{2}$ and $\mathrm{H}_{2} \mathrm{O}_{2}$ is produced by application of $10-20 \mathrm{~mm}$ glucose to dorsal root ganglia neurons that leads to lipid oxidation and neuronal death. IGF-I prevents this glucose-induced death, in part through decreased ROS production (55-56). Oxidative stress in diabetes and the development of complications is closely correlated. As the disease progresses, depending upon the level of glycemic control, plasma lipid peroxidation products increases and antioxidant potential decreases (57). Similarly, oxidative stress is linked to preclinical features of disease, such as vascular endothelial activation that can lead to atherosclerosis (58). In women, due to the early increment of oxidative stress in diabetes is more pronounced and this may cause increased cardiovascular disease patients (59).

\section{Skin Diseases}

Skin, which is the largest human body organ, is constantly exposed to an array of chemical and physical environmental pollutants and thus provides a major interface between the environment and the body (60). Exposure of skin in UV radiation or xenobiotics drugs generates ROS in excessive quantities that quickly swamp tissue antioxidants and their pathways (61). Infiltrating activated leukocytes that possess abundant systems capable of generating these species, are an additional source of oxygen radicals in skin as well as in other organs, among which are $\mathrm{O}_{2}$ and hypochlorite an important sources of ROS in situ. Many of these agents are capable to generate ROS intrinsically or their metabolites such as redox active quinines. Many of them are involved in the pathogenesis of multiple skin disorders/allergic reactions/neoplasms $(63,64)$. eicosanoids driving cutaneous inflammation is another important pathway, which are generated from arachidonic acid $(\mathrm{AA})$ by the enzyme prostaglandin $\mathrm{H}$ synthetase that generates hydroxyl-endoperoxides. The eicosanoids including the leukotrienes and the prostaglandins are an important inflammatory mediators. Inducible nitric oxide synthase is another pro-oxidant enzyme present in skin, which is induced in infiltrating leukocytes and other phagocytic cells, and produces NO. NO interacts with respiratory burst generated OS to form a highly unstable reactive species $\mathrm{ONOO}^{-}$, that can damage DNA thereby producing point mutations, deletions, or rearrangements (65, 66). Following UVB exposure Urocanic acid is another molecule in skin that undergoes cis-trans isomerization and is likely involved in the immunosuppressive as well as photo aging effects of sunlight and is also known to prolong skin-graft survival time, and affect natural killer cell activity (67). UVA irradiation of trans-urocanic acid generates $\mathrm{O}_{2}$ radical ion that after initiating c-jun N-terminal kinase (JNK) signaling, leads to interstitial collagenase induction as well as the synthesis of IL-1 and IL- 6 a proinflammatory cytokines, in UVA-irradiated fibroblasts and this revelation is determined by enhanced production of 5a-cholesterol hydroperoxide, a marker of $\mathrm{O}_{2}$ generation. However, endogenously generated chromophores like nicotinamide adenine dinucleotide (reduced form)/nicotinamide adenine dinucleotide phosphate (reduced form), tryptophan, riboflavin, etc. modulates this response (68).

\section{The Ageing process}

It has been proposed that the although mitochondria express a variety of protective defenses (antioxidant and repair enzymes as well as low molecular weight antioxidants), oxidation of proteins and the slow accumulation of DNA lesions resulting from the continuous formation of ROS may contribute to the ageing process (69). increased formation of ROS is caused due to effect in rate of electron flow through some these lesions, which supports the observed correlation between the rate of mitochondrial $\mathrm{O} 2-\cdot$ and $\mathrm{H} 2 \mathrm{O} 2$ formation and at the same time lifespan among several species (70). Deficiencies in the mitochondrial DNA repair system directly correlates to ageing process. Since mitochondrial DNA does not contain histones, and therefore it is less protected against oxidative stress than the nuclear DNA. Consequently, the a 10- to 20-fold increase in the content of 8-hydroxyguanine, the product of guanine oxidation is shown by mitochondrial DNA (71). Because of this mtDNA damage may indirectly inhibit respiration and stimulate ROS formation, since the mitochondrial chromosome codes for some electron carriers. A human condition that causes premature ageing, Cockayne syndrome, has been associated with a deficiency in the mitochondrial enzyme required for DNA repair that catalyses the removal of 8-hydroxyguanine (72). A more direct correlation between oxidative stress and ageing are shown by other studies. First, further linking oxidative stress with ageing, there is a correlation between accumulation of oxidized proteins and lifespan (69). Overexpression of catalase and SOD results in a $25 \%$ increase in the lifespan of Drosophila melanogaster is shown by another study in a more direct approach (73-75).

\section{NEURODEGENERATIVE DISEASES}

\section{Amyotrophic Lateral Sclerosis (ALS)}

Amyotrophic lateral sclerosis (ALS) is a neurological disease that has been associated with oxidative stress. About $10 \%$ of the cases of familial ALS have been linked to a mutation in the gene coding for CuZn SOD (76). Misfolding will be occur due to this mutation, and the effective import of this enzyme to the inter-membrane space will be prevented, thus increasing the steady-state concentration of O2-• in this compartment, a process that may lead to apoptosis (77).

\section{Leber Hereditary Optic Neuropathy}

Another genetic mutation indirectly associated with increased formation of ROS is the mutation in one of the subunits of Complex I responsible for Leber hereditary optic neuropathy that causes neuronal apoptosis. In a recent article, the investigators manipulated the expression of MnSOD in order to increase the intramitochondrial steady state of O2-• in normal cells, resulting in the same histopathological changes observed in Leber's disease (78). 


\section{Alzheimer's Disease \& Parkinson's disease (Mechanisms of Oxidative Stress: ROS Production by Mitochondrial Dysfunction and NADPH Oxidase)}

In many neurodegenerative diseases including AD, PD, Huntington's disease, ALS, PSP, Friedreich's ataxia, Neurodegeneration with brain iron accumulation, and optic atrophy, mitochondrial pathology is evident (Figure 3). The respiratory chain dysfunction and oxidative stress, reduced ATP production, calcium dysregulation, mitochondrial permeability transition pore opening, peturbation in mitochondrial dynamics, and deregulated mitochondrial clearance shows whole spectrum of mitochondrial dysfunction. From the hippocampus and platelets of AD patients, as well as in AD animal models and AD cybrid cells, in mitochondria the complex IV activity is reduce (79).

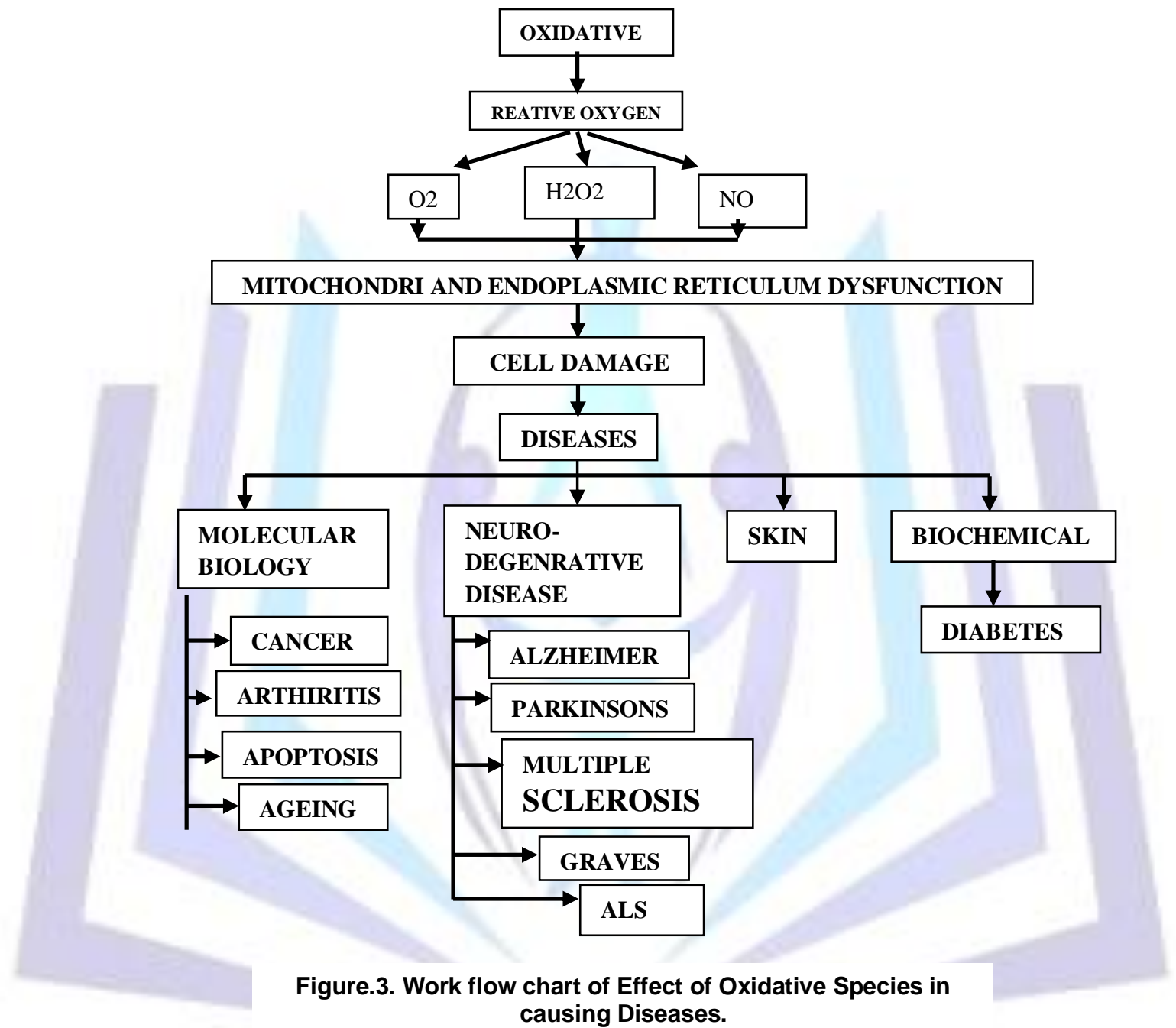

Consequent increase in ROS production and opening of the PTP due to deregulation of calcium homeostasis has been demonstrated in $A D$, with $\beta A$ causing increased cytoplasmic calcium levels and mitochondrial calcium overload. $\beta A$ is responsible for induced opening of PTP in isolated mitochondria and primary astrocytes $(80,81)$. In brains of AD patients, activation of NOX2 has been demonstrated (82), which shows an upregulation of NOX1 and NOX3 in early stage postmortem AD brain (83). The role of NADPH oxidase in AD has also been suggested at a cellular level. Direct activation of NADPH oxidase in rat primary culture of microglial cells and human phagocytes is induced by Amyloid-beta ( $\beta A)(84-$ 86). Through B-class scavenger receptor CD36, $\beta A$ activates microglial NOX (87). Active NADPH oxidase transfers protons across the membrane and for normal functioning, requires opening of an ion/anion channel for charge compensation (88). In $\beta A$ activated microglia, by blocking the charge compensatory mechanism of NADPH oxidase, inhibition of CLIC1 channel, inhibited superoxide production and protect cells (89). By its antioxidant properties, Neuroprotective effect of some endogenous compounds, such as hormone melatonin is induced (90). $\beta A$ also activates NADPH oxidase by massive NO production and the generation of peroxynitrate and inducing calcium entry into astrocytes but not neurons (91) resulting in the generation of oxidative stress, which depolarises the mitochondrial membrane and, in combination with calcium, induces opening of the mitochondrial permeability transition pore (mPTP) as well as changing membrane structure through activation of phospholipase $C(92)$. This oxidative stress signal is passed to more vulnerable neighboring neurons than astrocytes. It has therefore been suggested that due to increased oxidant production by NADPH oxidase, depletion of GSH in astrocytes could diminish GSH release from astrocytes and consequently deplete GSH in 
neurons. Although, in some studies it is evident that $\beta A$ and the presenilins exhibit the ability to activate NADPH oxidase in primary neurons (91). In Parkinson's disease (PD), oxidative stress has been demonstrated in both the rotenone and MPTP-induced toxin models showing further activation of NADPH oxidase (NOX2) in microglia (193). Furthermore, pharmacological inhibition of NADPH oxidase is able to protect mesencephalic dopaminergic neuronal (N27) cells against MPP+-mediated dopaminergic degeneration (94). Interestingly, the NADPH oxidase is activated by Oxidative Medicine and high cytosolic calcium concentration, leading to overproduction of superoxide inhibitingt the plasmalemmal glucose transporter resulting in deregulation of mitochondrial metabolism (95). In cytosol of neocortical neurons the $\beta A$ is able to activate production of $\mathrm{H} 2 \mathrm{O} 2$ (96). Inhibitor of $\mathrm{XO}$ allopurinol significantly suppressed $\mathrm{OH}^{\text {; }}$ suggesting a potential role for $\mathrm{XO}$ in the oxidative stress associated with PD and AD (97). In different neuronal populations neurodegenerative disease is the selective vulnerability that may affected in a progressive and often stereotyped manner. However, the susceptible neuronal population varies between diseases, despite oxidative stress being implicated as the major pathogenic process in all of them and neurons were affected, there must be additional factors that determine the selective cell death in each disease. Certain neuronal groups have high intrinsic levels of oxidative stress and are therefore more vulnerable to additional disease-related oxidative stress. Neurons that have long axons and multiple synapses have high bioenergetic requirements for axonal transport or long-term plasticity and will render these groups of neurons far more sensitive to degeneration than other neuronal groups. Different neuronal groups exhibit different degrees of oxidative stress. The exposure of neurons at higher levels of cytosolic dopamine; that is, dopaminergic neurons are also exposed to additional oxidative stress produced by the metabolism of dopamine by MAO (which generates hydrogen peroxide) as well as the autooxidation of dopamine (which generates superoxide). Thus endogenous dopamine, as well as exogenous treatment with levodopa (used in PD) may be a further source of oxidative stress that may worsen pathogenesis (98, 99). However, it should be noted that the MAO-induced metabolism of dopamine and production of hydrogen peroxide have an important role in physiological calcium signaling in astrocytes and is not solely a pathological process (100). One interesting hypothesis has emerged from the discovery that adult substantia nigra pars compacta dopaminergic neurons have an autonomous pacemaker mechanism that utilizes L-type calcium channels resulting in intracellular calcium oscillations showing for the vulnerability of specific neuronal groups in Parkinson's disease. As the repeated and persistent entry of calcium into cells needs to be counterbalanced by ATP demanding pumps to restore the calcium concentration creates a metabolic stress for such neurons. In fact it has been demonstrated that the opening of these kinds of ion channels results in higher levels of OS in the mitochondria of such neurons (101).

\section{Multiple Sclerosis Lesions}

Production of ROS is accomplished by two principally different mechanisms: activation of free radical producing those enzymes which are involved in oxidative burst, and by mitochondrial dysfunction (102-104). The result through microarray studies shows a deterioration of mitochondrial function in active multiple sclerosis lesions, which appears to be related to active degeneration of myelin, oligodendrocytes, neurons and axon (105-107). After formation of bruise the mitochondrial numbers and activity of enzyme is increase, apparently reflecting the increased metabolic demand of demyelinated axons in the lesions or a reaction to chronic mitochondrial insult (107-108). Furthermore, cells containing oxidized lipids and oxidized DNA are mainly concentrated at these sites (109) and the clearest damage to mitochondria in oligodendrocytes and axons is seen in this area (105-107). Experimental studies suggest that oxidative tissue damage under these conditions is most likely mediated by peroxynitrite (110). ROS is produced by activated microglia through classical Nox2 dependent oxidative burst. This view is supported by several observations. First, p22phox and gp91phox are more abundantly expressed in active multiple sclerosis lesions compared with other oxidases, such as MPO (111-113). Secondly, the co-expression of different components of the Nox2 complex in the same microglia cells indicates that these complexes are functionally active. Thirdly, the expression of p22phox and gp91phox are less intense in macrophages. Potential functional importance of Nox2 complexes in inflammatory demyelinating brain lesions are shown by the protective effect of gp91phox gene deletion in animals with autoimmune encephalomyelitis $(114,115)$. In vitro, microglia toxicity is, in part, mediated through ROS production by the Nox1 complex (116).

\section{Oxidative Stress and the Thyroid Gland}

Synthesis of thyroid hormones requires formation of the hydrogen peroxide; a highly reactive oxidant. $\mathrm{H}_{2} \mathrm{O}_{2}$ and $\mathrm{I}$ are immediately used in peroxidation reaction that is catalysed by thyroid peroxidase (117). In a healthy thyroid, ROSs are produced in an area that is located at the apical pole of the cell in microvilli, where $\mathrm{H} 2 \mathrm{O} 2$ is consumed either during the hormone synthesis or by antioxidant systems (118). However, Th1-induced ROS production causes ROS accumulation both in the cytoplasm and in nuclei, where it can become toxic. As hydrogen peroxide and iodine are cosubstrates in thyroid hormone production, iodine inhibits hydrogen peroxide production. Tobacco smoke contains thyocyanate that blocks iodine transport into thyrocite. This could increase $\mathrm{H} 2 \mathrm{O} 2$ production and oxidative load, especially when associated with other environmental factors. Increase in ROS balanced by the increase in AOD would lead to minimal inflammation, but unopposed increase in ROS would lead to strong inflammation and cell necrosis. Reducing ROS would lead to inflammation reduction and vice versa $(119,120)$

\section{Graves' disease (Peripheral Tissues and Retro-orbital Tissues)}

Graves' disease is characterized by increased oxidative stress. However, thyroid hormones, per se, induce OS, which is tissue and species specific. Even in subclinical hyperthyroidism, oxidative stress and antioxidative response seem to be increased $(121,122)$. It seems that the oxidative stress-induced activation of the NF-kappaB pathway might play a role in the autoimmune response in hyperthyroidism (123). Therefore, when antioxidant supplementation is added to methimazole, euthyroidism is more rapidly achieved $(124,125)$. Hyperthyroidism is associated with increased lipid 
peroxidation products in rat liver and with increased activities of glutathione peroxidase, superoxide dismutase, and catalase in the liver (126). Liver oxidative stress increases quickly after increase of thyroid hormones (127). In rat kidney and testis, hyperthyroidism is associated with increased oxidative stress and lipid peroxidation (128-130). Hyperthyroidism is also associated with increased oxidative stress and oxidative damage to lipids and genomic DNA in the aortic wall (131). During hyperthyroidism, there is an increase in myocardial oxidative stress that is associated with lipid peroxidation and protein oxidation. Myocardial antioxidant enzyme activities elevation accompanied by protein expression induction occurs after four weeks of hyperthyroidism (132). It seems that oxidative stress plays an important role in cardiac hypertrophy, by the redox activation of AKT1 and JUN/FOS signaling pathways (133). Redox imbalance due to hyperthyroidism induces adaptation of antioxidant systems, also inducing ERK1/2 activation and leading to development of cardiac hypertrophy (134). This response may involve the thyroid hormone-induced upregulation of HSP70 (135). In skeletal muscle, hyperthyroidism causes increased oxidative stress associated with oxidative modification in myosin heavy chain causing the decrease in force production (136). Enhanced adipogenesis and overproduction of glycosaminoglycans causes an increase in orbital volume and fibrosis of the extraocular muscles (137) causing Grave's disease. In orbital fibroblasts, obtained from subjects with severe grave orbitopathy, superoxide radicals induce a dose dependent cellular proliferation (138). IL-1 $\beta$ is produced by activated macrophages and is an important mediator of the inflammatory response. Adding IL-1 $\beta$ to cultures of retroorbital fibroblasts causes an increased oxygen-free radical production in a dosedependent manner. This is observed both in Graves' and in control cultures. Total intracellular superoxide dismutase (SOD) activity was stimulated by IL-1 $\beta$, both in control and in Graves' cultures. HSP72 is a stress inducible form of cytosolic HSP70. Its expression is induced by the environmental stress, such as heat shock, anoxia, and ischemia. Antioxidants, methimazole, and PTU reduced H2O2-induced HSP72 expression, and to a lesser degree heat-induced HSP72 expression (139-141). In patients with Graves' orbitopathy, there was significant correlation between TSH receptor antibody levels and 8-hydroxy-2_-deoxyguanosine (a biomarker of DNA damage) content (142). It should be noted that smoker had higher urinary 8-OhdG level than never-smokers, and that smoking was significant factor in multivariate analysis. Study by Tsai et al. implies that smoking-induced oxidative stress contributes to the pathogenesis of Graves orbitopathy $(143,144)$. One of the major forms of DNA damage induced by OS is 7, 8-dihydro-8-oxoguanine, referred in an abbreviated way as 8 -oxoguanine (8-oxoG). This type of DNA damage is repaired by the base excision repair pathway.

\section{CONCLUSION}

Oxidative stress plays an important role in human pathogenesis. Accumulation and eneration Of (ROS) Reactive Oxygen Species within cells are detrimental and can exacerbate the disease progression. Therefore, several strategies have been studied to prevent or slow down ROS-mediated damages The concept of oxidative stress simply implied that ROS/RNS are toxic species because of their highly reactive nature. The production of ROS is mainly accomplished by two principally different mechanisms: activation of free radicalproducing enzymes, such as those involved in oxidative burst, and by mitochondrial dysfunction an increment in the generation of Reactive Oxygen Species such as superoxide, hydrogen peroxide and hydroxyl radical is the cause of oxidation and modification of structure of membrane lipids, cellular proteins and nucleic acids. In summary, ROS formation is part of normal cellular physiology. Excessive or abnormal free radical production and accumulation result in oxidative stress which responsible for a significant pathology in many diseases, including Cancer, Diabetes and neurodegenerative diseases. Investigations into the specific molecular targets of ROS in different pathway and the specific signaling mechanisms will be important for the understanding of biology and of different diseases for future research purposes.

\section{REFERENCES}

[1] Harman, D. 1993. Drug Aging, Proc Natl Acad Sci U S A. 3, 60-80.

[2] Fridovich, I. 1995. Superoxide radical and superoxide dismutases. Annual Review of Biochem. 64, 97-112

[3] Vazifeh, D., Abdelghaffar, H., and Labro, M.T. 2002. Effect of telithromycin (HMR 3647) on polymorphonuclear neutrophil killing of Staphylococcus aureus in comparison with roxithromycin. Antimicrob Agents Chemother, 46 , 1364-1374

[4] Antunes, F., and Cadenas, E. 2000. Estimation of H2O2 gradients across biomembranes. FEBS Lett. 475,121126.

[5] Pieper, G.M., Langenstroer, P., and Gross, G.J. 1993. Hydroxyl radicals mediate injury to endotheliumdependent relaxation in diabetic rat. Molecular and Cellular Biochemistry, 122,139-145

[6] Ghafourifar, P., Bringold, U., Klein, S.D., and Richter, C. 2001. Mitochondrial nitric oxide synthase, oxidative stress and apoptosis, Biol. Signals Recept., 10,57-65

[7] Suzuki, T., Tatsuoka, H., Chiba, T., Sekikawa, T., Nemoto, T., Moriya, H., Sakuraba, S., and akaya, H. 2001. Beneficial effects of nitric oxide synthase inhibition on the recovery of neurological function after spinal cord injury in rats. Naunyn Schmiedebergs Arch Pharmacol. 363,94-100

[8] Bruhwyler, J., Chleide, E., Liegeois, J.F., and Carreer,. F. 1993 Nitric oxide: a new messenger in the brain. Neuroscience Biobehavi. Rev. 17,373-384

[9] Huang, P.L., and Lo, E.H. 1998. Genetic analysis of NOS isoforms using nNOS and eNOS knockout animals. Prog Brain Res. 118,13-25

[10] Violi, F., Marino, R., Milite, M.T., and Loffredo, L. 1999. Nitric oxide and its role in lipid peroxidation. Diabetes Metab Res Rev. 15, 283-288 
[11] Hunt, C.R., Sim, J.E., Sullivan, S.J., Featherstone, T., Golden, W., Kapp-Herr, C.V., Hock, R.A., Gomez, R.A,. Parsian, A.J., and Spitz, D.R. 1998. Genomic instability and catalase gene amplification induced by chronic exposure to oxidative stress. Cancer Res. 58, 3986-3992.

[12] Mills, E.M., Takeda, K., Yu, Z.X., Ferrans, V., Katagiri, Y., Jiang, H., Lavigne, M.C., Leto, T.L., and Guroff, G. 1998. Nerve growth factor treatment prevents the increase in superoxide produced by epidermal growth factor in PC12 cells. J. Biol. Chem. $27322165-22168$.

[13] Rollet, E., Grange, M.J., Elbim, C., Marquetty, C., Gougerot, M.A., and Pasquier, C. 1998. Hydroxyl radicals as a potential intracellular mediator of polymorphonuclear neutrophil apoptosis, Free Rad. Biol. Med. 24 563-572.

[14] Tanaka, K., Pracyk, J.B., Takeda, K., Yu, Z.X., Ferrans, V.J., Deshpande, S.S., Ozaki, M., Hwang, P.M., Lowenstein, C.J., Irani, K., and Finkel, T. 1998 Expression of Id1 results in apoptosis of cardiac myocytes through a redox-dependent mechanism. J. Biol. Chem. 273, 25922-25928.

[15] Mills, E.M., Takeda, K., Yu, Z.X., Ferrans, V., Katagiri, Y., Jiang, H., Lavigne, M.C., Leto, T.L., and Guroff, G. 1998. Nerve growth factor treatment prevents the increase in superoxide produced by epidermal growth factor in PC12 cells. J. Biol. Chem., 273, 22165 \pm 22168 .

[16] Floyd, R.A. 1990. The role of 8-hydroxydeoxyguanosine in carcinogenesis. Carcinogenesis, 11, 1447-1450.

[17] Guyton, K.Z., Liu, Y., Gorospe, M., Xu, Q., and Holbrook, N.J., 1996. Activation of mitogen -activated protein Kinase by H2O2: role in cell survival following oxidant injury. J. Biol. Chem., 271, 4138-4142.

[18] Bae, Y.S., Kang, S.W., Seo, M.S., Baines, I.C., Tekle, E., Chock, P.B., and Rhee, S.G., 1997 Epidermal growth factor (EGF)-induced generation of hydrogen peroxide. J. Biol. Chem., 272, 217-221.

[19] Manna, S.K., Zhang, H.J., Yan, T., Oberley, L.W., and Aggarwal, B.B. 1998 Overexpression of manganese superoxide dismutase suppresses tumor necrosis factor-induced apoptosis and activation of nuclear transcription factor-b and activated protein. J. Biol. Chem., 273, 13245-13254.

[20] Musonda, C.A., and Chipman, J.K. 1998. Quercetin inhibits hydrogen peroxide (H2O2)-induced NFkB DNA binding activity and DNA damage in HepG2 cells. Carcinogenesis, 19, 1583-1589.

[21] Limoli, C.L., Hartmann, A., Shephard, L., Yang, C., Boothman, D.A., Bartholomew, J., and Morgan, W.F. 1998 Apoptosis reproductive failure and oxidative stress in chinese hamster ovary cells with compromised genomic integrity. Cancer Res., 58, 3712-3718.

[22] Behn, M., Qun, S., Pankow, W., Havemann, K., and Schuermann, M. 1998 Frequent detection of ras and p53 mutations in brush cytology samples from lung cancer patients by a restriction fragment length polymorphismbased 'enriched PCR' technique. Clin. Cancer Res., 4, 361-371.

[23] Hockenbery, D.M., Oltvai, Z.N., Yin, X.M., Milliman, C.L., and Korsmeyer, S.J. 1993. Bcl-2 functions in an antioxidant pathway to prevent apoptosis. Cell, 75, 241-251.

[24] Bojes, H.K., Datta, K., Xu, J., Chin, A., Simonian, P., Nunaez, G., and Kehrer, J.P. 1997. Bcl-xL overexpression attenuates glutathione depletion in FL5.12 cells following interleukin-3 withdrawal, Biochem. J., 325, 115-119.

[25] Amstad, P., Moret, R., and Cerutti, P. 1994. Glutathione peroxidase compensates for the hypersensitivity of $\mathrm{Cu}, \mathrm{Zn}$ superoxide dismutase overproducers to oxidant stress. J. Biol. Chem., 269, 1606-1609.

[26] Czene, S., Tibaeck, M., and Harms, M. 1997. PH-dependent DNA cleavage in permeabilized human fibroblasts, Biochem. J. 323, 337-341.

[27] Dimmeler, S., Haendeler, J., Sause, A., and Zeiher, A.M. 1998. Nitric oxide inhibits APO-1/Fasediated cell death, Cell Growth Differ. 9, 415-422.

[28] Tamarit, J., Cabiscol, E., and Ros, J. 1998. Identification of the major oxidatively damaged proteins in Escherichia coli cells exposed to oxidative stress. J. Biol., Chem. 273 3027-3032.

[29] Cai, J., and Jones, D.P. 1998. Superoxide in apoptosis: Mitochondrial generation triggered by cytochrome c loss. J. Biol. Chem., 273, 11401-11404.

[30] Karlberg, I., Lindahl, K., Loew, H., and Mattsson, A. 1981. Role of aerobic conditions in the control of cell proliferation. Int. Arch. Allergy Appl. Immunol., 65, 250-256.

[31] Suzuki, Y., Ono, Y., and Hirabayashi, Y. 1998. Rapid and specific reactive oxygen species generation via NADPH oxidase activation during Fas-mediated apoptosis. FEBS Lett., 425, 209-212.

[32] Toledano, B.J., Bastien, Y., Noya, F., Baruchel, S., and Mazer, B. 1997. Platelet-activating factor abrogates apoptosis induced by cross-linking of the surface $\mathrm{IgM}$ receptor in a human B lymphoblastoid cell line. J. Immunol., 158, 3705-3715.

[33] Burdon, R.H., Gill, V., and Rice, C. 1989. Cell proliferation and oxidative stress. Free Radic. Res. Commun., 7,149-159.

[34] Burdon, R.H., Gill, and V., Rice, C. 1990. Oxidative stress and tumour cell proliferation, Free Radic. Res. Commun. 11, 65-76.

[35] Murrell, G.A. 1992. An insight into Dupuytren's contracture, Ann. Roy. Coll. Surg. Engl. 74, 156-160.

[36] Burdon, R.H., Gill, V., and Alliangana, D. 1996. Hydrogen peroxide in relation to proliferation and apoptosis in BHK-21 hamster Rbroblasts, Free Radic. Res. 24, 81-93.

[37] Kazzaz, J.A., Xu, J., Palaia, T.A., Mantell, L., Fein, A.M., and Horowitz, S. 1996. Cellular oxygen toxicity. Oxidant injury without apoptosis, J. Biol. Chem. 271, 15182-15186.

[38] Vassilev, A., Ozer, Z., Navara, C., Mahajan, S., and Uckun, F.M. 1999. Bruton's tyrosine kinase as an inhibitor of the Fas/CD95 death-inducing signaling complex, J. Biol. Chem., 274, 1646-1656.

[39] Gutierrez, M.I., Cherney, B., Hussain, A., Mostowski, H., Tosato, G., Magrath, I., and Bhatia, K. 1999. Bax is frequently compromised in Burkitt's lymphomas with irreversible resistance to Fas-induced apoptosis, Cancer Res., 59, 696-703. 
[40] Zwacka, R.M., Dudu, L., Epperly, M.W., Greenberger, J.S., and Engelhardt, J.F. 1998. Redox gene therapy protects human IB-3 lung epithelial cells against ionizing radiation-induced apoptosis, Hum. Gene Ther., 9, 13811386.

[41] Brenneisen, P., Wenk, J., Klotz, L.O., Wlaschek, M., Briviba, K., Krieg, T., and Sies, H. 1998. Central role of Ferrous/Ferric iron in the ultraviolet B irradiation mediated signaling pathway leading to increased interstitial collagenase (matrix-degrading metalloprotease (MMP)-1) and stromelysin-1 (MMP-3) mRNA levels in cultured human dermal fibroblasts, J. Biol. Chem., 273, 5279-5287.

[42] Valavanidis, A., Balomenou, H., Macropoulou, I., and Zarodimos, I. 1996. A study of the synergistic interaction of asbestos fibers with cigarette tar extracts for the generation of hydroxyl radicals in aqueous buffer solution, Free Radic. Biol. Med., 20, 853-858.

[43] Jacob, A.K., Hotchkiss, R.S., DeMeester, S.L., Hiramatsu, M., Karl, I.E., Swanson, P.E., Cobb, J.P., and Buchman, T.G. 1997. Endothelial cell apoptosis is accelerated by inorganic iron and heat via an oxygen radical dependent mechanism, Surgery, 122 243-254.

[44] World health organization. Definition, diagnosis and classification of diabetes mellitus and its complications 1999 , $1-59$.

[45] Saikat, D., Sekhar, K., Ranabir, S., and Subhash, C. 2008. Antidiabetic effect of matured fruits of Diospyros peregrine in alloxon-induced diabetic rats. International Journal of Green Pharmacy. 95-99.

[46] Michael, J.C., james, M.C., Vinay, and Robbins, K. 2000. Pathalogic basis of disease, "The pancreas". 6th ed. Harcourt publisher, 902-929

[47] John, W., Baynes and Suzanne, R. 1999. Role of Oxidative Stress in Diabetic Complications. Diabetes, 48,1-9.

[48] Moussa, S.A. 2008. Oxidative stress in Diabetes Mellitus. Romanian J Biophys, 18, 225-236.

[49] Boguslaw, L. 2001. Pathophysiology of Oxidative stress in Diabetes mellitus. Journal of Diabetes and its Complications, 15, 203-210.

[50] Klaus, A. and Heribert, H. 2004. Reactive Oxygen Species: Metabolism, Oxidative Stress, and Signal Transduction. Annu. Rev Plant Biol., 55, 373-99.

[51] Cetin, I., Engin, M., Goziikara, and Akin, V. Erythrocyte Catalase Activities in Chronic Leukemias. 2005 Journal of Diabetes and its Complications, 25, 203-210.

[52] Russell, J.W., Sullivan, K.A., Windebank, A.J., Herrmann, D.N., and Feldman, E.L. 1999 Neurons undergo apoptosis in animal and cell culture models of diabetes. Neurobiol Dis 6, 347-363

[53] Russell, J.W., Golovoy, D., Vincent, A.M., Mahendru, P., Olzmann, J.A., Mentzer, A., and Feldman, E.L. 2002 High glucose induced oxidative stress and mitochondrial dysfunction in neurons. FASEB J., 16, 1738-1748

[54] Vinik, A.I. 1999 Diabetic neuropathy: pathogenesis and therapy. Am J Med., 107, 17S-26S

[55] Folmer, V., Soares, J.C., and Rocha, J.B. 2002 Oxidative stress in mice is dependent on the free glucose content of the diet. Int. J. Biochem. Cell Biol., 34, 1279-1285

[56] Tsai, E.C., Hirsch, I.B., Brunzell, J.D., and Chait, A. 1994 Reduced plasma peroxyl radical trapping capacity and increased susceptibility of LDL to oxidation in poorly controlled IDDM. Diabetes, 43, 1010-1014

[57] Elhadd, T.A., Kennedy, G., Hill, A., McLaren, M., Newton, R.W., Greene, S.A., and Belch, J.J. 1999. Abnormal markers of endothelial cell activation and oxidative stress in children, adolescents and young adults with type 1 diabetes with no clinical vascular disease. Diabetes Metab Res. Rev., 15, 405-411

[58] Marra, G., Cotroneo, P., Pitocco, D., Manto, A., Di Leo MA, Ruotolo, V., Caputo, S, Giardina, B., Ghirlanda, G., and Santini, S.A. 2002. Early increase of oxidative stress and reduced antioxidant defenses in patients with uncomplicated type 1 diabetes: a case for gender difference. Diabetes Care, 25,370-375

[59] Athar, M. 2002. Oxidative stress and experimental carcinogenesis. Indian J. Exp. Biol ., 40, 656-67

[60] Sander, C.S., Chang, H., Hamm, F., Elsner, P., and Thiele, J.J. 2004. Role of oxidative stress and the antioxidant network in cutaneous carcinogenesis. Int. J. Dermatol. 43, 326-35

[61] Cerutti, P., Shah, G., Peskin, A., and Amstad, P. 1992. Oxidant carcinogenesis and antioxidant defense. Ann. NY Acad. Sci., 663, 158-66

[62] Briganti, S., and Picardo, M., 2003. Antioxidant activity, lipid peroxidation and skin diseases. What's new. J Eur Acad Dermatol Venereol, 17, 663-9

[63] Black, H.S. 2004. ROS: a step closer to elucidating their role in the etiology of light-induced skin disorders. J. Invest. Dermatol., 122, 13-15

[64] Ryter, S.W., and Tyrrell, R.M. 2000. The heme synthesis and degradation pathways: role in oxidant sensitivity. Heme oxygenase has both proand antioxidant properties. Free Radic Biol. Med. 28, 289-309

[65] Lee, J.L., Mukhtar, H., Bickers, D.R., Kopelovich, L., and Athar, M. 2003. Cyclooxygenases in the skin: pharmacological and toxicological implications. Toxicol Appl. Pharmacol., 192, 294-306

[66] Haralampus, N., Ransom, C., Ye, T., Rozanowska, M., Wrona, M., and Sarna, T. 2002 Photogeneration and quenching of reactive oxygen species by urocanic acid. J. Am. Chem. Soc. 124, 3461-8

[67] Hanson, K.M., and Simon. J.D., 1998. Epidermal transurocanic acid and the UV-A-induced photoaging of the skin. Proc. Natl. Acad. Sci. 95, 10576-8

[68] Barja, G., 1999. Mitochondrial oxygen radical generation and leak: sites of productin states

[69] Lopez, M., Perez, R., Rojas, C., Cadenas, S., and Barja, G. 1993. Maximum life span in vertebrates: Relationship with liver antioxidant enzymes glutathione system ascorbate urate sensitivity to peroxidation true malondialdehyde in vivo $\mathrm{H} 2 \mathrm{O} 2$, and basal and maximum aerobic capacity. Mech. Ageing Dev., 70, 177-199.

[70] McCord, J.M., and Fridovich, I. 1988. Superoxide dismutase: the first twenty years (1968-1988). Free Radic. Biol. Med., 5, 363-369.

[71] Orr, W.C., and Sohal R.S. 1994. Extension of life-span by over expression of superoxide dismutase and catalase in Drosophila melanogaster. Science, 263, 1128-1130. 
[72] Ames, B.N., Shigenaga, M.K., and Hagen, T.M. 1995. Mitochondrial decay in aging. Biochim. Biophys. Acta., $1271,165-170$.

[73] Borras, C., Sastre, J., Garcia, D., Lloret, A., Pallardo, F.V., and Vina, J. 2003. Mitochondria from females exhibit higher antioxidant gene expression and lower oxidative damage than males. Free Radic. Biol. Med. 34, 546-552.

[74] Valentine, J.S., and Hart, P.J. 2003. Misfolded CuZnSOD and amyotrophic lateral sclerosis. Proc. Natl. Acad. Sci. U S A., 100, 3617-3622.

[75] Asdell, S.A, Doornenbal, H., Joshi, S.R., and Sperling, G.A, 1967. The effects of sex steroid hormones upon longevity in rats. J. Reprod Fertil., 14, 113-120.

[76] Du, H., Guo, L., Yan, S., Sosunov, A. A., McKhann, G. M., and. Yan, S. S. 2010 "Early deficits in synaptic mitochondria in an Alzheimer's disease mouse model," Proceedings of the National Academy of Sciences of the United States of America, 107, 18670-18675

[77] Qi, X., Lewin, A.S,. Hauswirth, W.W., and Guy, J. 2003. Optic neuropathy induced by reductions in mitochondrial superoxide dismutase. Invest Ophthalmol Vis. Sci., 44, 1088-1096.

[78] Sohal, R.S., Agarwal, S., Dubey, A., and Orr, W.C. 1993. Protein oxidative damage is associated with life expectancy of houseflies. Proc. Natl. Acad. Sci. U S A. 90, 7255-7259.

[79] Abramov, A. Y., Fraley, C.T., and Diao C. 2000. Targeted polyphosphatase expression alters mitochondrial metabolism and inhibits calcium-dependent cell death. Proceedings of the National Academy of Sciences of the United States of America, 104, 18091-18096

[80] Abramov, A. Y., and Duchen, M. R. 2005. The role of an astrocytic NADPH oxidase in the neurotoxicity of amyloid beta peptides. Philosophical Transactions of the Royal Society B, 360, 2309-2314

[81] Shimohama, S., Tanino, H., and Kawakami N. 2000. Activation of NADPH oxidase in Alzheimer's disease brains. Biochemical and Biophysical Research Communications, 1,5-9

[82] De La Monte S. M., and Wands, J. R. 2006. Molecular indices of oxidative stress and mitochondrial dysfunction occur early and often progress with severity of Alzheimer's disease. Journal of Alzheimer'sDisease, 9,167-181

[83] Park, L., Anrather, J., and Zhou P. NADPH oxidasederived reactive oxygen species mediate the cerebrovascular dysfunction induced by the amyloid $\beta$ peptide. Journal of Neuroscience, 25, 1769-1777

[84] Park, L., Zhou, P., and Pitstick, R. 2008. Nox2-derived radicals contribute to neurovascular and behavioral dysfunction in mice overexpressing the amyloid precursor protein. Proceedings of the National Academy of Sciences of the United States of America, vol. 105, 1347-1352

[85] Della Bianca, V., Dusi, S., Bianchini, E., Dal Pra, I., and Rossi, F. 1999. $\beta$-amyloid activates the O2 forming NADPH oxidase in microglia, monocytes, and neutrophils. A possible inflammatory mechanism of neuronal damage in Alzheimer's disease. Journal of Biological Chemistry, 274, 15493-15499, 1999.

[86] Wilkinson, B., Koenigsknecht, J., Grommes, C., Lee, C. Y. D., and Landreth, G. 2006. Fibrillar $\beta$-amyloidstimulated intracellular signaling cascades require Vav for induction of respiratory burst and phagocytosis in monocytes and microglia. Journal of Biological Chemistry, 281, 20842-20850

[87] DeCoursey, T. E., Morgan, D., and Cherny, V.V. 2003. The voltage dependence of NADPH oxidase reveals why phagocytes need proton channels. Nature, 422, 531-534

[88] Milton, R. H., Abeti, R., and Averaimo S. 2008. CLIC1 function is required for $\beta$-amyloid-induced generation of reactive oxygen species by microglia. Journal of Neuroscience, 28, 11488-11499

[89] Abramov, Y. A., Kasymov, V. A., and Zinchenko, V. P. 2008. Betaamyloid activates synthesis of nitric oxide in hyppocampal astrocytes and causes death of neurons. Biologicheskie Membrany, 25, 11-17

[90] Brown, G. C. 2007. Mechanisms of inflammatory neuro degeneration: INOS and NADPH oxidase Biochemical Society Transactions, 35, 1119-1121

[91] Hicks, J. B., Lai, Y., and Sheng W., et al. 2008. Amyloid- $\beta$ peptide induces temporal membrane biphasic changes in astrocytes through cytosolic phospholipase A2. Biochimica et Biophysica Acta., 11, 2512-2519.

[92] Gao, H. M., Liu, B., and Hong, J. S. 2003. Critical role for microglial NADPH oxidase in rotenone-induced degeneration of 10 Oxidative Medicine and Cellular Longevity dopaminergic neurons. Journal of Neuroscience, 23, 6181-6187

[93] Anantharam, V., Kaul, S., Song, C., Kanthasamy, A., and Kanthasamy, A. G. 2007. Pharmacological inhibition of neuronal NADPH oxidase protects against 1-methyl-4-phenylpyridinium (MPP+)-induced oxidative stress and apoptosis in mesencephalic dopaminergic neuronal cells. NeuroToxicology, 28, 988-997

[94] Gandhi, S., Wood-Kaczmar, A., and Yao Z., et al. 2009. PINK1 associated Parkinson's disease is caused by neuronal vulnerability to calcium-induced cell death. Molecular Cell, 33, 627-638

[95] Kaminsky Y. G., and Kosenko, E. A. 2008 Effects of amyloid-beta peptides on hydrogen peroxide-metabolizing enzymes in rat brain in vivo, Free Radical Research, 42, 564- 573

[96] Obata, T., Kubota, S., and Yamanaka, Y. 2001. Allopurinol suppresses para-nonylphenol and 1-methyl-4phenylpyridinium ion (MPP+)-induced hydroxyl radical generation in rat striatum. Neuroscience Letters, 306, 912 ,

[97] Muller, T. 2011. Motor complications, levodopa metabolism and progression of Parkinson's disease. Expert Opinion on Drug Metabolism and Toxicology, 7, 847-855

[98] Muller T., and Muhlack, S. 2011. Cysteinyl-glycine reduction as marker for levodopa-induced oxidative stress in Parkinson's disease patients. Movement Disorders, 26, 543-546

[99] Vaarmann, A., Gandhi, S., and Abramov, A. Y. 2010 Dopamine induces Ca2+ signaling in astrocytes through reactive oxygen species generated by monoamine oxidase. Journal of Biological Chemistry. 285, 25018-25023

[100] Surmeier, D. J., Guzman, J. N., Sanchez J., and Goldberg, J. A. 2011. The origins of oxidant stress in parkinson's disease and therapeutic strategies, Antioxidants and Redox Signaling. 14, 1289-1301 
[101] Van,J., Witte, M.E., Schreibelt, G., and de Vries H,E. 2011 Radical changes in multiple sclerosis pathogenesis. Biochem Biophys Acta. 1812, 141-50.

[102] Van, J., Drexhage, J., Flor, T., Gerritsen, W., van der Valk, P., and deVries, H.E. 2010, Nrf2 and DJ1 are consistently upregulated in inflammatory multiple sclerosis lesions. Free Radic. Biol. Med., 8, 1283-9.

[103] Van Horssen, J., Schreibelt, G., Drexhage, J., Hazes, T., Dijkstra, C.D., and van der Valk, P., et al. Severe oxidative damage in multiple sclerosis lesions coincides with enhanced antioxidant enzyme expression. Free Radical Biol. Med. 45, 1729-37.

[104] Mahad, D., Ziabreva, I., Lassmann, H., and Turnbull, D. 2008. Mitochondrial defects in acute multiple sclerosis lesions. Brain, 131, 1722-35.

[105] Mahad, D., Lassmann, H., and Turnbull, D. 2008. Mitochondria and disease progression in multiple sclerosis. Neuropathol Appl. Neurobiol. 34, 577-89.

[106] Mahad, D., Ziabreva, I., Campbell, G., Lax, N., Hanson, P.S., and Lassmann, H., et al. 2009 Mitochondrial changes within axons in multiple sclerosis. Brain, 132, 1161-74.

[107] Lucchinetti, C., Bruck, W., Parisi, J., Scheithauer, B., Rodriguez, M., and Lassmann, H. 2000 Heterogeneity of multiple sclerosis lesions: implications for the pathogenesis of demyelination. Ann. Neurol. 47, 707-17

[108] Haider, L., Fischer, M.T., Frischer, J.M., Bauer,J., Hoftberger, R., and Botond, G., et al. Oxidative damage and neurodegeneration in multiple sclerosis lesions. Brain, 134, 1914-24.

[109] Zeis, T., Propst, A., Steck, A.J., Stadelmann, C., Bruck, W., and Schaeren, N. 2009. Molecular changes in white matter adjacent to an active demyelinating lesion in early multiple sclerosis. Brain Pathol., 19, 459-66

[110] Marik, C., Felts, P., Bauer, J., Lassmann, H., and Smith, K.J. 2007. Lesion genesis in a subset of patients with multiple sclerosis: a role for innate immunity?. Brain, 130, 2800-15.

[111] Gray, E., Thomas, T.L., Betmouni, S., Scolding, N., and Love, S. 2008. Elevated myeloperoxidase activity in white matter in multiple sclerosis. Neurosci. Lett. 442,195-8.

[112] Gray, E., Thomas, T.L., Betmouni, S., Scolding, N., and Love, S. 2008. Elevated activity of microglial expression of myeloperoxidase in demyelinated cerebral cortex in multiple sclerosis. Brain. Pathol., 18, 86-95

[113] Li, J., Baud, O., Vartanian, T., Volpe, J.J., and Rosenberg, P.A. 2005. Peroxynitrite generated by inducible nitric oxide synthase and NADPH oxidase mediates microglial toxicity to oligodendrocytes. Proc. Natl. Acad. Sci. USA. 102, 9936-41.

[114] Li, S., Vana, A.C., Ribeiro, R., and Zhang, Y. 2011. Distinct role of nitric oxide and peroxinitrite in mediating oligodendrocyte toxicity in culture and in experimental autoimmune encephalomyelitis. Neuroscience, 184, 10719.

[115] Cheret, C., Gervais, A., Lelli, A., Colin, C., Amar, L., and Ravassard, P., et al. 2008 Neurotoxic activation of microglia is promoted by a nox1 dependent NADPH oxidase. J. Neurosci., 28, 12039-51.

[116] Larsen, P. R., Davies, T. F., Schlumberger, M., and Hay, I. D. 2008. "10" in Williams Textbook of Endocrinology, H. M. Kronenberg, S. Melmed, K. S. Polonsky, and P. R. Larsen, Eds., pp. 299-332, Saunders Elsevier, 2008.

[117] Song, Y., Driessens, N., and Costa, M. et al., 2007. Roles of hydrogen peroxide in thyroid physiology and disease. The Journal of Clinical Endocrinology and Metabolism, 92, 3764-3773

[118] Poncin, S., Colin, I. M., and Decallonne B., et al., N-acetylcysteine and 15 deoxy- $\Delta 12,14$-prostaglandin J2 exert a protective effect against autoimmune thyroid destruction in vivo but not against interleukin-1 $\alpha /$ interferon $\gamma$ induced inhibitory effects in thyrocytes in vitro, The American Journal of Pathology, 177, 219-228

[119] Poncin, S., Gerard, A. C., and Boucquey, M., et al., Oxidative stress in the thyroid gland: from harmlessness to hazard depending on the iodine content. Endocrinology, 149, 424-433

[120] Venditti, P., and Di Meo, S. 2006. Thyroid hormone-induced oxidative stress, Cellular and Molecular Life Sciences, 63, 414-434

[121] Cetinkaya, A., Kurutas, E. B., Buyukbese, M. A., Kantarceken, B., and Bulbuloglu, E. 2005. Levels of malondialdehyde and superoxide dismutase in subclinical hyperthyroidism. Mediators of Inflammation, 2005, 5759

[122] Nandakumar, D. N., Koner, B. C., and Vinayagamoorthi R., et al., 2008. Activation of NF- $k$ B in lymphocytes and increase in serum immunoglobulin in hyperthyroidism: possible role of oxidative stress. Immunobiology, 213, 409-415

[123] Makay, B., Makay, O., and Yenisey, C., et al. 2009. The interaction of oxidative stress response with cytokines in the thyrotoxic ratpls there a link? Mediators of Inflammation, vol. 2009, Article ID 391682, 7

[124] Bednarek, J., Wysocki, H., and Sowinski, J. 2005. Oxidative stress peripheral parameters in Graves' disease: the effect of methimazole treatment in patients with and without infiltrative ophthalmopathy. Clinical Biochemistry, 38, $13-18$

[125] Messarah, M., Boumendjel, A., and Chouabia, A., et al., 2010. Influence of thyroid dysfunction on liver lipid peroxidation and antioxidant status in experimental rats, Experimental and Toxicologic Pathology, 62, 301-310

[126] Chattopadhyay, S., Sahoo, D. K., Roy, A., Samanta, L., and Chainy, G. B. N. 2010. Thiol redox status critically influences mitochondrial response to thyroid hormone-induced hepatic oxidative injury: a temporal analysis. Cell Biochemistry and Function, 28, 126-134

[127] Sahoo, D. K., Roy, A., Bhanja, S., and Chainy, G. B. N. 2005. Experimental hyperthyroidism-induced oxidative stress and impairment of antioxidant defence systemin rat testis. Indian Journal of Experimental Biology, 43, 1058-1067

[128] Zamoner, A., Barreto, K. P., and Filho, D.W., et al. 2007. Hyperthyroidism in the developing rat testis is associated with oxidative stress and hyperphosphorylated vimentin accumulation. Molecular and Cellular Endocrinology, 267, 116-126 
[129] Mogulkoc, R., Baltaci, A. K., Oztekin, E., Ozturk, A., and Sivrikaya, A. 2005 Short-term thyroxine administration leads to lipid peroxidation in renal and testicular tissues of rats with hypothyroidism. Acta Biologica Hungarica, 56, 225-232

[130] Moulakakis, K. G., Poulakou, M. V., and Paraskevas, K. I., et al., 2007. Hyperthyroidism is associated with increased aortic oxidative DNA damage in a rat model. In Vivo., 21, 1021- 1026

[131] Araujo, A. S. R., Ribeiro, M. F. M., and Enzveiler, A., et al. 2006. Myocardial antioxidant enzyme activities and concentration and glutathione metabolism in experimental hyperthyroidism. Molecular and Cellular Endocrinology, 249, 133-139

[132] Araujo, A. S. R., Schenkel, P., and Enzveiler A. T., et al. 2008. The role of redox signaling in cardiac hypertrophy induced by experimental hyperthyroidism. Journal of Molecular Endocrinology, 41, 423-430

[133] Araujo, A. S., Fernandes, T., Ribeiro, M. F., Khaper, N., and Bell o-Klein, A. 2010. Redox regulation of myocardial Erk 1/2 phosphorylation in experimental hyperthyroidism: role of thioredoxin- peroxiredoxin system. Journal of Cardiovascular Pharmacology, 56, 513-517

[134] Pantos, C., Malliopoulou, V., and Mourouzis, I., et al., 2006. Hyperthyroid hearts display a phenotype of cardioprotection against ischemic stress: a possible involvement of heat shock protein 70 . Hormone and Metabolic Research, 38, 308-313

[135] Yamada, T., Mishima, T., Sakamoto, M., Sugiyama, M., Matsunaga, S., and Wada, M., Oxidation of myosin heavy chain and reduction in force production in hyperthyroid rat soleus. Journal of Applied Physiology, 100, 1520-1526

[136] Eckstein, A. K., Johnson, K. T., Thanos, M., Esser, J., and Ludgate, M. 2009. Current insights into the pathogenesis of Graves' orbitopathy. Hormone and Metabolic Research, 41, 456-464

[137] Burch, H. B., Lahiri, S., Bahn, R. S., and Barnes, S. 1997. Superoxide radical production stimulates retroocular fibroblast proliferation in Graves ophthalmopathy, Experimental Eye Research, 65, 311-316

[138] Tsan M. F., and Gao, B. 2009. Heat shock proteins and immune system. Journal of Leukocyte Biology, 85, 905910

[139] Williams J. H. H., and Ireland, H. E. 2008. Sensing danger-hsp72 and hmgb1 as candidate signals. Journal of Leukocyte Biology, 83, 489-492

[140] Heufelder, A. E., Wenzel, B. E., and Bahn, R. S. 1992. Methimazole and propylthiouracil inhibit the oxygen free radical-induced expression of a 72 kilodalton heat shock protein in Graves' retroocular fibroblasts. The Journal of Clinical Endocrinology and Metabolism, 74, 737-742

[141] Tsai, C. C., Wu, S. B., and Cheng, C. Y., et al. 2010. Increased oxidative DNA damage, lipid peroxidation, and reactive oxygen species in cultured orbital fibroblasts from patients with Graves ophthalmopathy: evidence that oxidative stress has a role in this disorder. Eye., 24, 1520-1525

[142] Tsai, C. C., Wu, S. B., and Cheng C. Y., et al. 2010. Increased oxidative DNA damage, lipid peroxidation, and reactive oxygen species in cultured orbital fibroblasts from patients with Graves ophthalmopathy: evidence that oxidative stress has a role in this disorder. Eye., 24, 1520-1525

[143] Tsai, C. C., Cheng, C. Y., and Liu, C. Y., et al. 2009. Oxidative stress in patients with Graves ophthalmopathy: relationship between oxidative DNA damage and clinical evolution, Eye., 23, 1725-1730

[144] Tanrikulu, S., Dogru, S., and Ozderya, A., et al. 2011. The 8-oxoguanineDNAN-glycosylase 1 (hOGG1) Ser326Cys variant affects the susceptibility to Graves' disease. Cell Biochemistry and Function, 29, 244-248

\section{Author' biography with Photo}

\section{Sandeep S Verma}

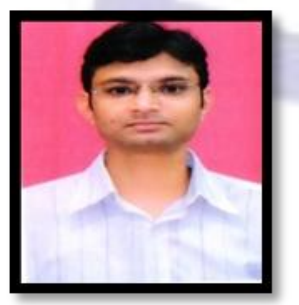

Sandeep S Verma has completed his Masters of Technology in Genomics and Proteomics from Sam Higginbottom Institute of Agriculture Technology and Sciences, Allahabad (India) in 2013. $\mathrm{He}$ did his bachelor of Technology in Biotechnology from Rajasthan Technical University, Kota, Rajasthan (India) in 2010. He has done his projects from Indian Institute of Toxicology Research, Lucknow in Embryo Toxicology and Environmental Carcinogenesis Divisions. His interest area is Stress Biology, Toxicology, Bioinformatics Molecular Biology and Nanotechnology.

\section{Swati Trivedi}

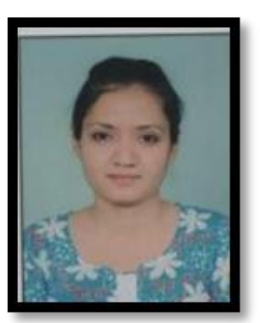

Swati Trivedi has completed her Masters in technology from Sam Higginbottom Institute of Agriculture Technology and Sciences, Allahabad whereas her Bachelors from Sardar Vallabhai Patel University of Agriculture and Technology, Meerut. She has done her project from Central Drug Research Institute, Lucknow and her work entitled Studies on Antibiotic Resistance in Gram Negative Pathogens. Her other experience encompasses area such as Molecular Biology, Bioinformatics, Phycology, Bioprocess Engineering and Biochemistry. 


\section{Dr Rajneesh Prajapat}

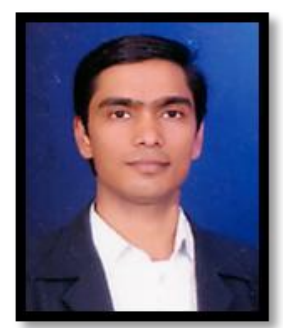

Dr. Rajneesh Prajapat has completed his Ph.D under the supervision of $\mathrm{Dr} \mathrm{R} \mathrm{K}$ Gaur entitled "Molecular and In Silico Characterization of Begomovirus Components Infecting Weeds of North India. He graduated from M.D.S University, Ajmer, Rajasthan (India) in 2003 and did M.Sc in Biotechnology from Universiry of Rajasthan, Jaipur, Rajasthan (India) in 2005 and obtains M.Phil in Environmental Biotechnology from Department of Environmental studies, M.D.S University, Ajmer, Rajasthan (India) in 2006. He has 30 publications and published 3 books on Bioinformatics and Molecular Virology.

\section{Avinash Marwal}

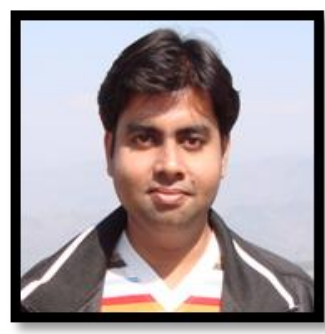

Avinash Marwal has submitted the thesis and completed his $\mathrm{PhD}$ from a DBT funded project (DBT project No. BT/PR13129/GBD/27/197/2009), under the supervision of Dr R. K. Gaur, Principal Investigator. He has 35 international publications in reputed journals and has command over various molecular, biotechnological and bioinformatics tools and techniques. His core interests are Homology Modeling, Molecular Docking, Biological Database development, In Silico drug designing, Plant Molecular Biology and Development of Transgenic Plants. 